\title{
ANOMALIAS DE SUSCETIBILIDADE MAGNÉTICA NO BATÓLITO GRANÍTICO DE TEIXEIRA (PROVÍNCIA DA BORBOREMA, NORDESTE DO BRASIL) E SUA RELAÇÃO COM A ZONA DE CISALHAMENTO DE ITAPETIM
}

\begin{abstract}
ROSENBERG G. LIMA ${ }^{1}$, CARLOS J. ARCHANJO ${ }^{2}$, JOSÉ WILSON P. MACEDO ${ }^{3}$ \& GERMANO MELO JÚNIOR
ABSTRACT MAGNETIC SUSCEPTIBILITY ANOMALIES IN THE TEIXEIRA BATHOLITH (BORBOREMA PROVINCE, NORTHEAST BRAZIL) AND ITS RELATIONSHIPS WITH THE ITAPETIM SHEAR ZONE The batholith granitic of Teixeira forms a large ENE-trending dyke of $80 \mathrm{~km}$ long and $10 \mathrm{~km}$ wide emplaced between pelitic metasediments and "Cariris Velhos" orthogneisses. The batholith was locally deformed by shear zones, the most important the NE-trending Itapetim Shear Zone (ISZ) which cross cut the eastern part of the dyke. In the gneiss situated in the southern part of the batholith, the ISZ host gold bearing quartz veins of the Itapetim District. A detailed magnetic study on the batholith show high susceptibilities $\left(>10^{-3} \mathrm{SI}\right)$ near fault and fractures zones that decrease in magnitude $\left(<0.5 \times 10^{-3} \mathrm{SI}\right)$ far from faulted zones. Thermomagnetic data and hysteresis parameters of the high susceptibility rocks revealed that the main carrier of susceptibility is a multidomian, Ti-poor magnetite. The mean coercivity around $4.8 \mathrm{mT}$ indicates that the magnetic properties are yielded by finest magnetite particles $(<10 \mu \mathrm{m})$. MEV backscaterring examination found nearly equant magnetite grains varying from $180 \mu \mathrm{m}$ down to $5 \mu \mathrm{m}$. Some grains display fine, discontinuous stripes of hematite occupying octahedral planes. Barite veins cross cutting the silicate framework and cavities infilled by microcrystalline quartz and TR-enriched allanite hosted in magmatic quartz crystal indicates that an oxidizing hydrothermal environment the gold mineralization is discussed.
\end{abstract}

Keywords: magnetic susceptibility, shear zones, granite magmatism, Borborema Province.

RESUMO O Batólito Granítico de Teixeira tem a forma de um dique de $80 \mathrm{~km}$ de extensão (leste-oeste) e $20 \mathrm{~km}$ de largura (norte-sul), encaixado entre metasedimentos pelíticos da Faixa Cachoeirinha-Salguciro e ortognaisses "Cariris Velhos". Na porção leste o batólito é seccionado por zonas de cisalhamento de natureza dúctil-frágil, destacando-se a Zona de Cisalhamento de Itapetim. O estudo da suscetibilidade magnética revelou que o plúton possui um comportamento dominantemente paramagnético, isto é, a suscetibilidade é em grande parte controlada pela presença dos minerais máficos, biotita e anfibólio. Entretanto, nos setores onde o batólito é afetado por fraturas e falhas, foram detectadas fortes anomalias de suscetibilidade, localmente atingindo $10^{-2} \mathrm{SI}$. O mineral responsável pelo aumento de sucetibilidade é a magnetita, conforme revelaram as curvas termomagnéticas e de histerese. Valores de coercividade na faixa de $4.8 \mathrm{mT}$ indicam que as propriedades magnéticas das rochas mais magneticamente suscetíveis estão relacionados à presença de grãos de magnetita relativamente finos (< $10 \mu \mathrm{m})$. 0 exame no microscópio eletrônico de varredura mostrou que a magnetita está associada à hematita e barita. Cavidades preenchidas por cristais fibrosos de alanita enriquecidos em elementos TR indicam processos de corrosão e precipitação promovidos pela passagem de um fluido relativamente oxidante. Como estes processos metassomáticos permearam a porção nordeste da Zona de Cisalhamento de Itapetim, a geração de magnetita (+ hematita, + barita) provavelmente possui relação com a precipitação/oxidação das mineralizações de ouro do Distrito de Itapetim.

Palavras-chave: suscetibilidade magnética, zonas de cisalhamento, magmatismo granítico, Província da Borborema.

\section{INTRODUÇÃO}

No mapa aeromagnético das Folhas Patos e Juazeirinho (PLGB, Sheid \& Ferreira, 1991, 1993), ambas situadas na Província da Borborema, foram definidos grandes alinhamentos magnéticos acompanhando principalmente zonas de falha e fratura. As zonas de cisalhamento regionais, como as de Patos e Afogados da Ingazeira (Fig. 1), são bem marcadas por alinhamentos magnéticos de direção E-W e NE-SW, respectivamente. Lineamentos magnéticos menores, de direção NW-SE, foram associados à zonas de fratura. Anomalias dipolares de forma elipsoidal, caracterizadas pela alternância de baixas $(<50 \eta \mathrm{T})$ e altas amplitudes $(>150 \eta \mathrm{T})$ magnéticas, são identificadas tanto no interior do Batólito Granítico de Teixeira (BT), como ao longo da Zona de Cisalhamento Itapetim (ZCI), situada a sul do BT (Fig. 2). Estas anomalias foram relacionadas à presença de corpos máficos em profundidade ou à diferenciações para litologias magnéticas associadas ao metamorfismo de contato (Sheid \& Ferreira, 1991). Os corpos gabróides que afloram na Folha Juazeirinho, próximos a Taperoá (PB), poderiam representar os equivalentes máficos em profundidade que delineam as anomalias em superfície.

A provável presença de rochas máficas e/ou processos de enriquecimento em minerais ricos em ferro ao longo dos lineamentos magnéticos, possui implicações no estudo da gênese e evolução das mineralizações auríferas dos distritos de Itapetim e Mãe D'Água. As mineralizações estão alojadas em veios de quartzo encaixados na ZCI que, na sua extremidade nordeste, seccionam a porção centro-oriental do BT (Fig. 2). Neste trabalho investiga-se a origem das anomalias/ lineamentos magnéticos no BT através do estudo da suscetibilidade magnética e da anisotropia. A escolha do B'T como área alvo para o estudo de anomalias magnéticas deve-se a sua homogeneidade litológica (granitos e granodioritos) e textural (equigranular média a fina) (Medeiros 1995). Esta homogeneidade possibilita o controle das variações mineralógicas que determinam a distribuição regional da suscetibilidade magnética e, consequentemente, a origem da variação e amplitude das anomalias. Não foram investigadas as propriedades magnéticas das rochas encaixantes, notadamente pela diversidade de tipos litológicos submetidos à forte metamorfismo regional.

O BATÓLITO DE TEIXEIRA O BT possui a forma de um dique de aproximadamente $80 \mathrm{~km}$ de comprimento por $10 \mathrm{~km}$ de largura. Ele ocupa a região limítrofe entre metapelitos da Faixa Cachoeirinha-Salgueiro e gnaisses migmatíticos "Cariris Velhos" (Santos e Medeiros 1997) (Fig. 2). Na sua porção oriental, o dique está alojado na junção dos cisalhamentos transcorrentes de Patos e Afogados da Ingazeira. Neste setor, o granito está fortemente afetado pela deformação

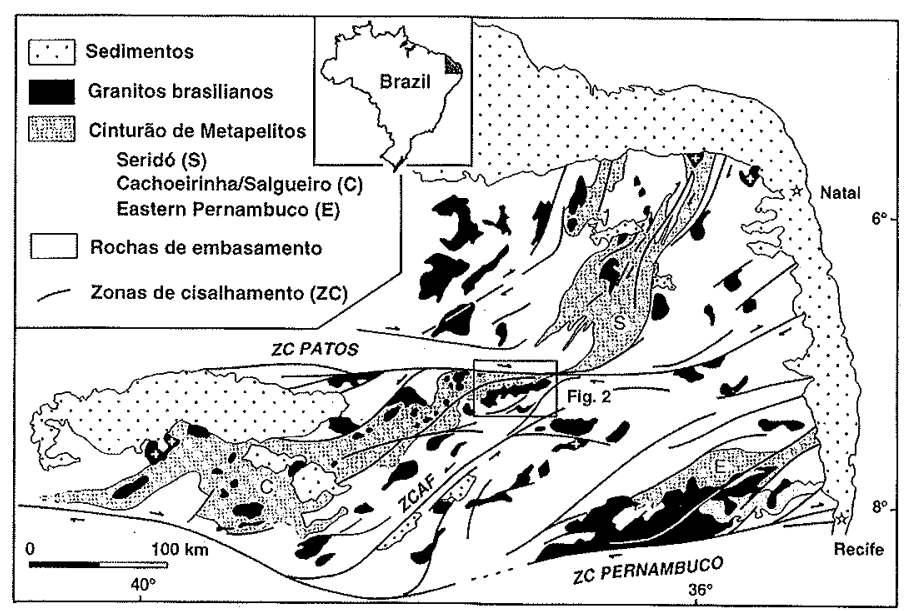

Figura I - Mapa geológico da parte oriental da Província Borborema. 
cisalhante que o transformou em um ortognaisse. Nas porções central e ocidental, o dique granítico é cortado por falhas e fraturas de direção NE-SW e NW-SE. Duas zonas de estrangulamento são observadas: uma na porção ocidental próximo a Mãe D'Água e outra no segmento oriental próxima a localidade de Cacimbas (Fig. 2). Estas zonas estranguladas coincidem com regiões de intenso fraturamento e forte atividade hidrotermal caracterizada pela formação, relativamente abundante, de veios ricos em turmalina e/ou quartzo. Afastando-se das zonas de estrangulamento o granito apresenta textura tipicamente magmática, equigranular (porções central e centro-ocidental) a porfirítica (stock de Mãe D'Água na extremidade ocidental). Parece haver uma forte relação entre as regiões estranguladas e a ocorrência de mineralizações, como notado na distribuição de ocorrências de ouro nos distritos de Mãe D’Água e Itapetim.

MÉTODOS DE TRABALHO A suscetibilidade magnética foi determinada através da amostragem de 138 estações distribuídas por quase toda a superfície do batólito (Fig. 3). Foi evitada a amostragem na extremidade oriental do corpo em virtude da forte foliação e recristalização imposta à rocha. Em cada estação de amostragem foram coletados 2 a 3 cilindros orientados de rocha, $\operatorname{com} 2,5 \mathrm{~cm}$ de diâmetro por $7 \mathrm{~cm}$ de comprimento. Os cilindros foram extraídos por meio de uma perfuratriz portátil movida por motor a gasolina. A amostragem foi feita na rocha sã e sem evidência de deformação no estado sólido. Foram evitadas zonas fraturadas, venuladas ou que apresentassem evidências de alteracão hidrotermal. No laboratório cada cilindro foi cortado para produzir duas amostras de $2,2 \mathrm{~cm}$ de comprimento contabilizando, para cada estação, 4 a 6 amostras orientadas de rocha.

Para o estudo das propriedades magnéticas do BT foram utilizados os valores médios de suscetibilidade e anisotropia magnética de cada estação. A suscetibilidade magnética foi medida em campos de baixa intensidade $\left(3,8 \times 10^{-4} \mathrm{~T} ; 920 \mathrm{~Hz}\right)$, utilizando-se um suscetibilímetro tipo KAPPABRIDGE KLY-2 do Laboratório de Propriedades Físicas dos Materiais Geológicos da UFRN. As magnitudes e orientações por amostra da suscetibilidade máxima $\left(k_{1}\right)$, intermediária $\left(k_{2}\right)$ e mínima $\left(k_{3}\right)$ foram determinadas segundo uma sequência de 15 medidas de suscetibilidade ao longo de diferentes direções na amostra. A magnitude média das direções principais de susceptibilidade de cada estação $\left(K_{i}\right)$ é definida como o valor médio de cada direção principal

$K_{i}=\sum_{i}^{n} k_{i} / n \quad$, onde $\mathrm{i}=1,2,3$.

SUSCETIBILIDADE E ANISOTROPIA MAGNÉTICA A magnitude de $K=1 / 3\left[K_{1}+K_{2}+K_{3}\right]$ e o grau de anisotropia $P(\%)=$ $100\left[\left(K, / K_{3}\right)-1\right]$ de cada estação estão apresentados na Tabela $1 . K$ varia de $0,06 \times 10^{-3} \mathrm{SI}$ a $16,46 \times 10^{-3} \mathrm{SI}$, com um valor médio de 1,73 $\times 10^{-3}$ SI. A maioria desses valores $(60,15 \%)$ são menores que $0,5 \times$ $10^{-3} \mathrm{SI}$ (Fig. 4), indicando que o BT possui suscetibilidade típica dos granitos a ilmenita $\left(K<10^{-3} \mathrm{SI}\right.$; Ishihara 1979). Em 30,43\% das amostras (42 estações), notadamente próximo a zonas de falhas, a susceptibilidade é superior a $1,0 \times 10^{-3} \mathrm{SI}$. A separação entre as rochas de baixa e alta suscetibilidade situa-se aproximadamente na parte mediana do dique, em torno da cidade de Teixeira.

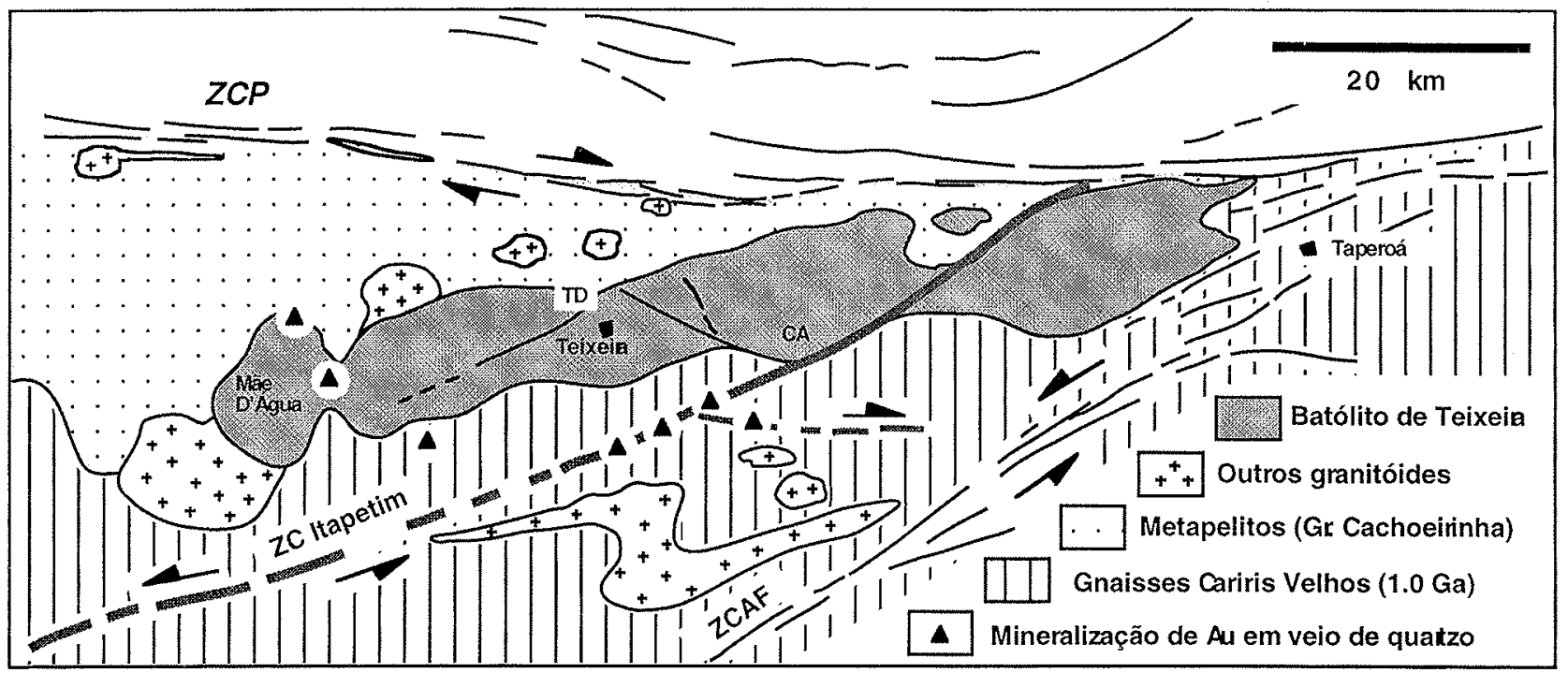

Figura 2 - Mapa geológico do Batólito de Teixeira. ZCP e ZCAF: Zonas de cisallamento de Patos e Afogados da Ingazeira, respectivamente. TD: Tem Do; CA Cacimbas.

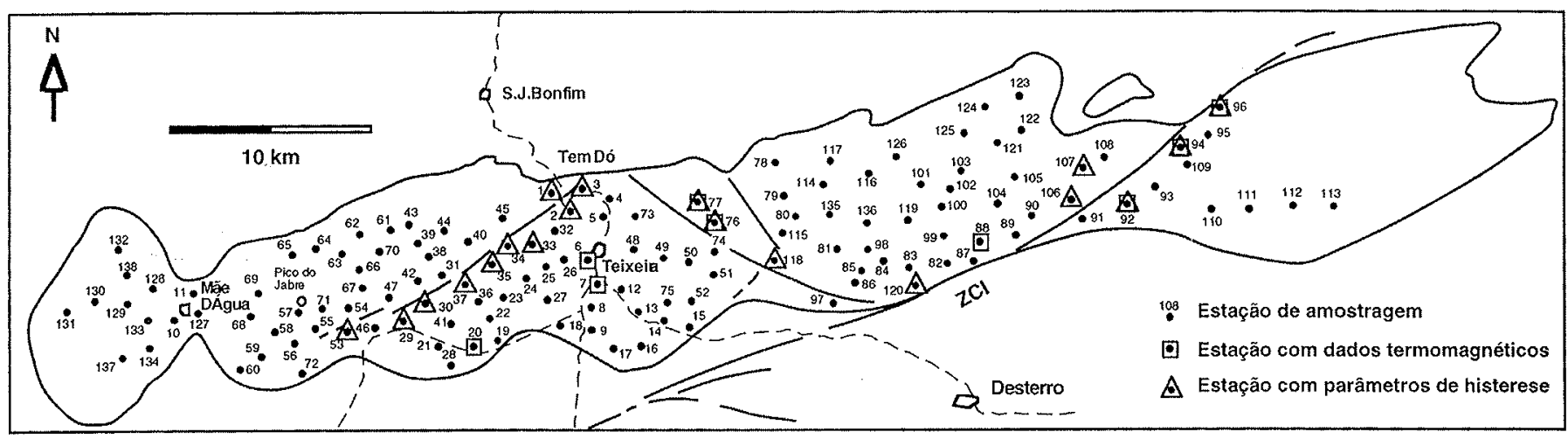

Figura 3 - Distribuição das estações de medida de susceptibilidade magnética do Batólito de Teixeira e localizaçäo das amostras submetidas a esudos teimomagnéticos e de histerese. ZCI: Zona de cisalhamento de Itapetim. 
Tabela I - Valores médios de suscetibilidade magnética $(K)$ e antisotropia $(P)$ do Batólito de Teixeira.

\begin{tabular}{|c|c|c|c|c|c|c|c|c|}
\hline Estação & $K\left(10^{-3} \mathrm{SI}\right)$ & $\mathrm{P}(\%)$ & Estação & $K\left(10^{-3} \mathrm{SI}\right)$ & $P(\%)$ & Estação & $K\left(10^{-3} \mathrm{SI}\right)$ & $P(\%)$ \\
\hline 1 & 0.39 & 16.83 & 51 & 0.13 & 6.61 & 101 & 0.19 & 4.22 \\
\hline 2 & 0.70 & 13.86 & 52 & 0.75 & 7.75 & 102 & 0.57 & 2.53 \\
\hline 3 & 0.15 & 2.49 & 53 & 1.85 & 7.99 & 103 & 0.63 & 6.36 \\
\hline 4 & 0.10 & 7.29 & 54 & 0.13 & 4.13 & 104 & 8.03 & 8.37 \\
\hline 5 & 0.19 & 3.93 & 55 & 0.13 & 4.71 & 105 & 3.72 & 8.90 \\
\hline 6 & 0.13 & 5.06 & 56 & 0.12 & 4.42 & 106 & 6.68 & 6.55 \\
\hline 7 & 0.17 & 5.13 & 57 & 0.10 & 4.99 & 107 & 16.46 & 14.01 \\
\hline 8 & 0.10 & 3.72 & 58 & 0.16 & 4.95 & 108 & 2.13 & 31.73 \\
\hline 9 & 1.27 & 3.96 & 59 & 1.56 & 10.79 & 109 & 4.23 & 10.31 \\
\hline 10 & 0.10 & 2.35 & 60 & 0.71 & 4.56 & 110 & 0.89 & 5.31 \\
\hline 11 & 0.14 & 1.51 & 61 & 1.10 & 9.41 & 111 & 8.65 & 8.74 \\
\hline 12 & 0.14 & 3.95 & 62 & 0.17 & 4.04 & 112 & 0.14 & 6.99 \\
\hline 13 & 0.15 & 3.39 & 63 & 0.12 & 3.59 & 113 & 6.04 & 9.03 \\
\hline 14 & 1.04 & 6.07 & 64 & 0.12 & 5.03 & 114 & 1.30 & 6.97 \\
\hline 15 & 0.10 & 2.79 & 65 & 0.12 & 4.52 & 115 & 0.16 & 2.14 \\
\hline 16 & 0.07 & 2.88 & 66 & 0.12 & 4.24 & 116 & 2.07 & 7.05 \\
\hline 17 & 0.14 & 4.38 & 67 & 0.13 & 3.80 & 117 & 1.88 & 25.22 \\
\hline 18 & 0.12 & 3.65 & 68 & 0.73 & 15.41 & 118 & 2.90 & 8.72 \\
\hline 19 & 0.13 & 3.36 & 69 & 2.63 & 10.56 & 119 & 0.23 & 7.26 \\
\hline 20 & 0.06 & 3.16 & 70 & 0.13 & 5.59 & 120 & 12.55 & 16.43 \\
\hline 21 & 0.22 & 5.75 & 71 & 0.14 & 4.12 & 121 & 0.45 & 5.90 \\
\hline 22 & 0.08 & 3.45 & 72 & 5.26 & 10.14 & 122 & 0.50 & 2.91 \\
\hline 23 & 0.18 & 11.10 & 73 & 0.29 & 7.62 & 123 & 0.71 & 6.97 \\
\hline 24 & 0.38 & 10.50 & 74 & 1.36 & 21.48 & 124 & 0.10 & 6.58 \\
\hline 25 & 1.00 & 15.37 & 75 & 0.83 & 8.43 & 125 & 0.58 & 7.60 \\
\hline 26 & 0.16 & 4.37 & 76 & 4.12 & 9.23 & 126 & 2.64 & 7.76 \\
\hline 27 & 0.14 & 2.88 & 77 & 6.69 & 13.25 & 127 & 0.11 & 3.18 \\
\hline 28 & 0.06 & 6.34 & 78 & 0.11 & 2.88 & 128 & 0.11 & 2.17 \\
\hline 29 & 1.77 & 13.28 & 79 & 0.10 & 4.31 & 129 & 0.10 & 1.82 \\
\hline 30 & 2.02 & 18.16 & 80 & 0.12 & 3.97 & 130 & 0.09 & 2.83 \\
\hline 31 & 0.16 & 3.71 & 81 & 0.13 & $7.3 \mathrm{I}$ & 131 & 0.09 & 1.77 \\
\hline 32 & 0.17 & 6.16 & 82 & 1.20 & 21.88 & 132 & 0.11 & 2.49 \\
\hline 33 & 0.92 & 11.07 & 83 & 7.74 & 10.24 & 133 & 0.09 & 1.78 \\
\hline 34 & 0.30 & 5.87 & 84 & 0.12 & 9.29 & 134 & 0.08 & 4.65 \\
\hline 35 & 1.68 & 10.49 & 85 & 0.13 & 5.92 & 135 & 0.12 & 5.05 \\
\hline 36 & 0.13 & 2.38 & 86 & 3.81 & 18.53 & 136 & 0.14 & 7.17 \\
\hline 37 & 0.25 & 5.81 & 87 & 1.31 & 3.04 & 137 & 0.10 & 2.12 \\
\hline 38 & 0.15 & 4.27 & 88 & 8.64 & 16.53 & 138 & 0.09 & 2.32 \\
\hline 39 & 0.14 & 4.16 & 89 & 2.65 & 18.93 & & & \\
\hline 40 & 0.09 & 4.96 & 90 & 10.61 & 5.36 & & & \\
\hline 41 & 0.08 & 1.70 & 91 & 13.77 & 15.22 & & & \\
\hline 42 & 0.16 & 4.95 & 92 & 4.06 & 7.17 & & & \\
\hline 43 & 0.90 & 8.86 & 93 & 13.44 & 30.40 & & & \\
\hline 44 & 0.14 & 3.42 & 94 & 0.34 & 11.27 & & & \\
\hline 45 & 0.15 & 4.20 & 95 & 8.03 & 12.19 & & & \\
\hline 46 & 0.15 & 5.17 & 96 & 9.70 & 69.32 & & & \\
\hline 47 & 0.13 & 5.08 & 97 & 0.18 & 2.95 & & $\cdot$ & \\
\hline 48 & 0.66 & 23.13 & 98 & 0.13 & 7.13 & & & \\
\hline 49 & 0.12 & 6.93 & 99 & 4.63 & 9.56 & & & \\
\hline 50 & 0.12 & 6.19 & 100 & 13.85 & 13.54 & & & \\
\hline
\end{tabular}

A distribuição regional de $K$ mostra uma forte correlação entre o aumento de suscetibilidade e a presença de zonas fraturadas e cisalhadas. Isto é particularmente evidente tanto na $\mathrm{ZCI}$ como nas zonas fraturadas de direção NW (Figs. 2 e 4). Afastando-se destes domínios, a suscetibilidade cai para valores inferiores a $0,5 \times 10^{-3} \mathrm{SI}$. Esses dois comportamentos diferenciam as regiões onde a suscetibilidade magnética apresenta uma forte contribuição dos minerais paramagnéticos, das regiões onde a fração ferromagnética s.l. domina a suscetibilidade (Rochette et al. 1992; Borradaile e Henry, 1997). As estimativas da contribuição paramagnética em rochas graníticas quando $K<0.5 \times 10^{-3} \mathrm{SI}$ situam-se acima de $60 \%$ da magnitude total de susceptibilidade (Benn et al. 1998; Archanjo et al. 1999). Para $K>10^{-3} \mathrm{SI}$ a suscetibilidade ferrimagnética domina amplamente, compreendendo $85 \%$ a $95 \%$ da suscetibilidade total da amostra (Archanjo et al. 1998).

A anisotropia magnética varia de $1 \%$ a $35 \%(P=0$ equivale a uma esfera), com um valor médio de $8 \%$. A maior parte dos valores de anisotropia $(76,81 \%$ ) são inferiores a $10 \%$ (Fig. 5), o que poderia in- 


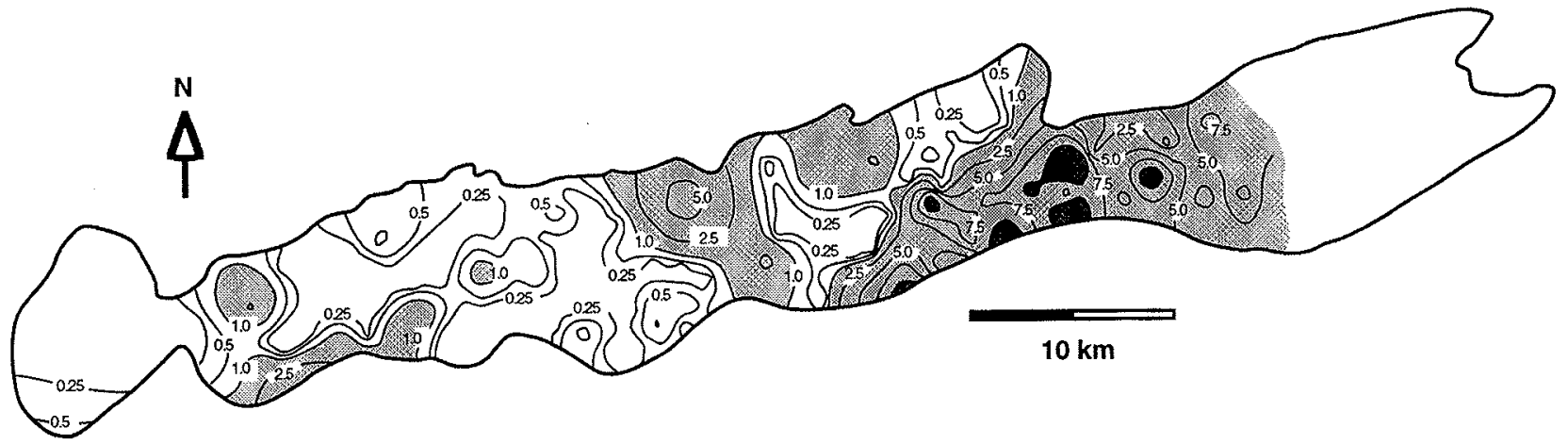

Figura 4 - Mapa de susceptibilidade magnética (linhas de contorno em $10^{-3}$ SI). Área sombreada: $K>1.0 \times 10^{-3} \mathrm{SI}$

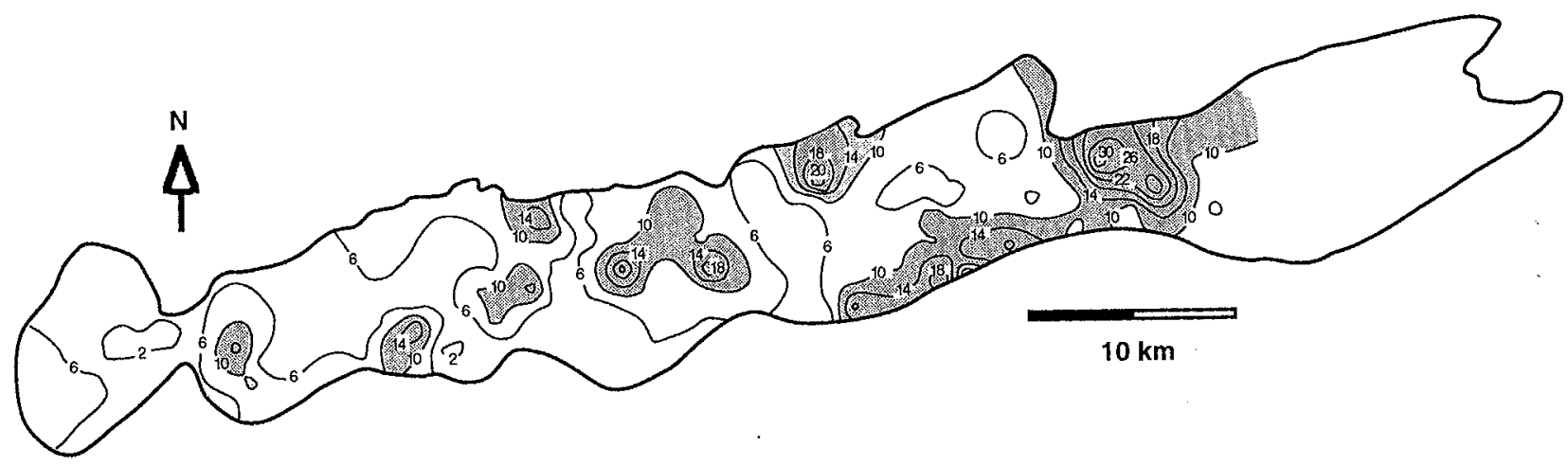

Figura 5 - Mapa de anisotropia de susceptibilidade. Área sombreada: $P>10 \%$

dicar uma forte contribuição dos minerais paramagnéticos à anisotropia (Bouchez 1997). Valores de $P>10 \%$ são indicativos da presença de minerais ferrimagnéticos e/ou de uma forte orientação preferencial da trama mineral. Como observado na suscetibilidade, o grau de $\mathrm{P}$ aumenta aproximando-se das zonas de cisalhamento e fratura. Em torno da ZCI, a anisotropia apresenta valores acima de $14 \%$ chegando, localmente, a $30 \%$ (Fig. 5). Uma segunda zona de direção NE-SW é bem delimitada na porção centro-ocidental do dique, prolongando-se até a localidade de Tem Dó próximo ao contato com filitos. No "alinhamento do Tem Do", a anisotropia magnética é geralmente superior a $10 \%$, alcançando localmente $14 \%$. A suscetibilidade magnética também marca relativamente bem o alinhamento do Tem Dó, principalmente na sua extremidade sudoeste. Valores relativamente elevados de suscetibilidade e anisotropia também são observados próximo a Mãe D'Água.

Nenhuma correlação direta foi observada entre $P$ e $K$ (Fig. 6). Contudo, pode-se notar que a variação de $P$ é mínima para $K<0,5 \times 10^{-3}$ SI e forte para $K>1,0 \times 10^{-3}$ SI. Isto sugere que a variação da anisotropia magnética depende tanto da mineralogia que domina a suscetibilidade, como da petrotrama. $O$ exame petrográfico das rochas com forte anisotropia mostrou uma discreta orientação preferencial das micas, geralmente associada à recristalização parcial de quartzo. Isto sugere que a cristalização de minerais ferrimagnéticos na zona de falha tem um impacto preponderante no grau de anisotropia magnética.

Tratamento Estatístico de $\boldsymbol{K}$ e $\boldsymbol{P}$ Para avaliar o significado da distribuição espacial da magnitude de $K$ e $P$ para cada uma das estações de amostragem, foi aplicado aos dados um tratamento estatístico. Este fundamenta-se no fato de que a informação transmitida pelos mapa de isovalores de $K$ (Fig. 4) e $P$ (Fig. 5) traduz a mistura de diversos componentes de variações inerentes à distribuiçãa de $K$ e $P$ nas diferentes escalas de observação. $O$ método empregado foi o da análise hierárquica de variância (Neter et al. 1990), que analisa e quantifica a contribuição relativa das variabilidades $\mathrm{S}_{\mathrm{A}}^{2}$ (entre amostras de um mesmo cilindro), $S_{c}^{2}$ (entre cilindros de uma mesma estação) e $S_{E}{ }^{2}$

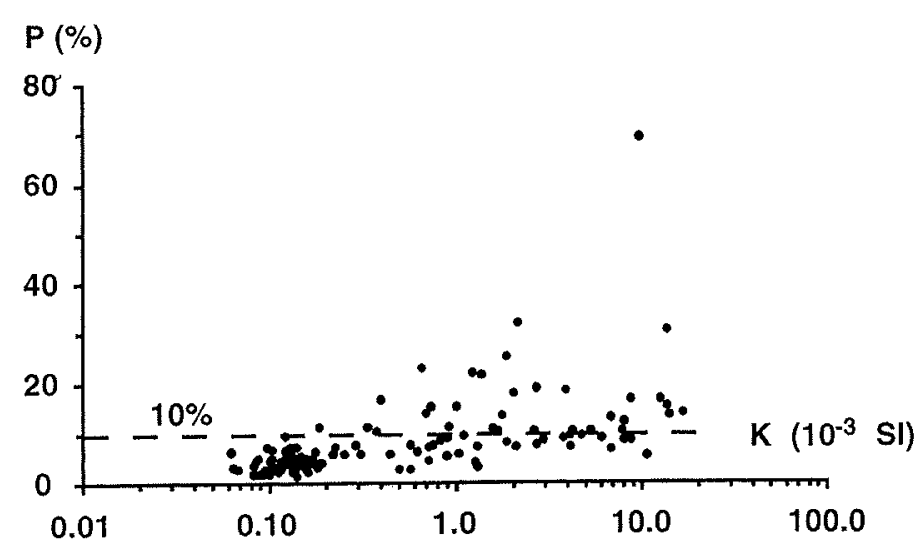

Figura 6 - Variação do grau de anisotropia (P\%) com a suscetibilidade magnética $\left(K_{m}\right)$.

(entre estações de amostragem ou regional) as quais, juntamente, formam a variabilidade total $S_{T}^{2}$ transmitida pelos mapas de isovalores de $K$ e $P$. O tratamento foi realizado com auxílio do software Statistica, módulo ANOVA-MANOVA, versão 6.0.

A Tabela 2 mostra os resultados obtidos após a aplicacão do referido tratamento. Foram utilizadas informações de 544 cilindros, equivalentes à 272 amostras, distribuídas nas 138 estações. Os resultados mostram que a diferença de suscetibilidade entre amostras de um mesmo cilindro é relativamente baixa $(1,58 \%)$, enquanto que a variabilidade entre cilindros de uma mesma estação é mais alta $(22,68 \%)$. Isto indica que $24,26 \%$ do relevo observado no mapa de isovalores de $K$ deve-se exclusivamente a heterogeneidades locais (entre cilindros por 
estação + entre amostras por cilindros). A variabilidade regional (entre estações de amostragem) foi de $75,74 \%$, de onde se conclui que a maior parte do relevo total pode ser seguramente referida a distribuição de $K$ entre estações do batólito.

A situação é semelhante no caso de $P$. A variabilidade de $\mathrm{P}$ entre amostras é de $10,67 \%$ e entre cilindros de $18,28 \%$. A maior fonte de heterogeneidade de $P$ é mesmo entre estações de amostragem $(71,05 \%)$, o que indica que o relevo exibido pelo mapa da Figura 7 decorre principalmente das variações de $P$ na escala do batólito.

Considerando que a suscetibilidade magnética do BT varia em função da proporção relativa entre as frações paramagnética e ferromagnética, os dados de $K \mathrm{e} P$ foram divididos em dois subgrupos, usando-se o valor de $K=0,5 \times 10^{-3} \mathrm{SI}$ como discriminador entre eles. As estações de amostragem para as quais o valor de $K$ é inferior a 0,5 $\times 10^{-3} \mathrm{SI}$ foram alocados no primeiro subgrupo (subgrupo inferior com 82 estações), enquanto que estações com valores de $K$ superiores a 0,5 $\times 10^{-3}$ SI foram analisados no segundo subgrupo (subgrupo superior com 54 estações). Em seguida os dados desses dois subgrupos foram processados segundo a análise hierárquica de variância, cujos resultados resumidos constam da Tabela 3 .

Tabela 2 - Resultados do tratamento estatístico para as variabilidades de $K$ (suscetibilidade) e $P$ (anisotropia). São mostrados os valores absolutos de cada variabilidade e entre parênteses a porcentagem dentro da variabilidade total.

\begin{tabular}{|c|c|c|c|c|}
\hline & $\begin{array}{l}\text { ENTRE } \\
\text { AMOSTRAS S }\end{array}$ & $\begin{array}{l}\text { ENTRE } \\
\text { CILINDROS } \mathrm{S}^{2} \text {. }\end{array}$ & $\begin{array}{l}\text { ENTRE } \\
\text { ESTAÇÕES S }\end{array}$ & TOTAL $S^{2}$ \\
\hline$K$ & $\begin{array}{l}189326,0 \\
(1,58 \%)\end{array}$ & $\begin{array}{l}2724234,0 \\
(22,68 \%)\end{array}$ & $\begin{array}{l}9096301,5 \\
(75,74 \%)\end{array}$ & $\begin{array}{l}12009861,5 \\
(100 \%)\end{array}$ \\
\hline$p$ & $\begin{array}{l}0,000656 \\
(10,67 \%)\end{array}$ & $\begin{array}{l}0,0011245 \\
(18,28 \%)\end{array}$ & $\begin{array}{l}0,004369 \\
(71,05 \%)\end{array}$ & $\begin{array}{l}0,0061495 \\
(100 \%)\end{array}$ \\
\hline
\end{tabular}

O subgrupo superior $\left(K>0,5 \times 10^{-3} \mathrm{SI}\right)$ apresenta uma baixa variabilidade entre amostras $(2,27 \%)$ e uma variabilidade mais alta entre cilindros $(32,84 \%)$. Isto significa que $35,11 \%$ da heterogeneidade de $K$ nesse subgrupo ocorre a nível de estação de amostragem, isto é, entre cilindros por estação + entre amostras por cilindro. A variabilidade de $K$ entre estaçóes, de $64,89 \%$, ainda pode ser considerada significativa, indicando que a distribuição dos valores de $K>0,5 \times 10^{-3}$ SI é em grande parte governada por contrastes elevados de $K$ dentro do corpo de Teixeira segundo a malha de amostragem $(2 \mathrm{~km} \times 2 \mathrm{~km})$. Nesse subgrupo, a variabilidade de $P$ entre amostras é de $11,71 \%$, entre cilindros de $23,53 \%$ e entre estações de $64,76 \%$. Isso indica que a heteregeneidade de $P$ entre estações com $K>0,5 \times 10^{-3}$ SI é principalmente de natureza regional, como no caso de $K$.

O subgrupo inferior $\left(K<0,5 \times 10^{-3} \mathrm{SI}\right)$ apresenta um comportamento diferente. A variabilidade de $K$ entre amostras é de $24,52 \%$, entre cilindros de $45,68 \%$ e entre estações de $29,80 \%$. Esses valores refletem uma menor disparidade na estrutura de variação de $K$ nas três escalas de análise de dados, indicando uma tendência de homogeneidade nas diferentes escalas. O mesmo acontece para $P$, onde a variabilidade entre amostras é de $35,89 \%$, entre cilindros de $18,4 \%$ e entre estações de $45,74 \%$.

Comparando os resultados dos dois subgrupos, pode-se concluir que os valores de $K$ e $P$ nas rochas de baixa suscetibilidade são mais homogêneos nas diferentes escalas de obtenção dos dados. Nas rochas de alta suscetibilidade, a variabilidade na sua maior parte é devido a contrastes em escala regional.

MINERALOGIA MAGNÉTICA As variações de suscetibilidade e anisotropia magnética estão fortemente controladas pela presença de minerais para- e ferrimagnéticos no granito. A caracterização destes minerais foi feita através da obtenção da temperatura de Curie, da determinação dos parâmetros do ciclo de histerese e da identificação mineralógica através do microscópio eletrônico (vide Fig. 3 para localização das amostras).

Temperatura de Curie As curvas termomagnéticas foram obtidas com o auxílio do forno $C S-2$ (para aquecimento e resfriamento da amostra) acoplado ao KAPPABRIDGE KLY-2. O conjunto mede valores discretos de suscetibilidade $(k)$ em fragmentos de rocha desde a temperatura ambiente e em intervalos sequenciados e crescentes de 3 ${ }^{\circ} \mathrm{C}$ até $680^{\circ} \mathrm{C}$ (ciclo de aquecimento). Ao atingir a temperatura máxi- ma, a amostra é resfriada até a temperatura ambiente com a suscetibilidade medida novamente a intervalos de $3{ }^{\circ} \mathrm{C}$ (ciclo de resfriamento). O resultado final é a obtenção de curvas termomagnéticas onde extraiu-se a temperatura de Curie (Tc) no ciclo de aquecimento e, no ciclo de resfriamento, controlou-se as eventuais transformações mineralógicas ocorridas no experimento. Foram selecionadas 10 amostras do BT para a confecção de curvas termomagnéticas, todas situadas em torno da ZCI no domínio de forte suscetibilidade.

As curvas de aquecimento e resfriamento de todas as amostras são extremamente semelhantes. Com o aumento da temperatura a suscetibilidade sofre leves flutuações ou aumenta suavemente (efeito Hopkinson). No intervalo de temperatura entre 570 e $575^{\circ} \mathrm{C}$, o valor de $k$ decresce abruptamente até valores negativos (Fig. 7). A queda da suscetibilidade neste intervalo de temperatura indica a presença da magnetita pobre em Ti (Hunt et al. 1995), cuja Tc situa-se em $575^{\circ} \mathrm{C}$ Não foi observado a presença de sulfetos magnéticos (pirrotita, greigita; $\mathrm{Tc} \sim 350^{\circ} \mathrm{C}$ ) ou hematita $\left(\mathrm{Tc}=670^{\circ} \mathrm{C}\right.$ ). A curva no ciclo de resfriamento é similar a curva de aquecimento, indicando que o experimento ocorreu sem modificações químicas significativas.

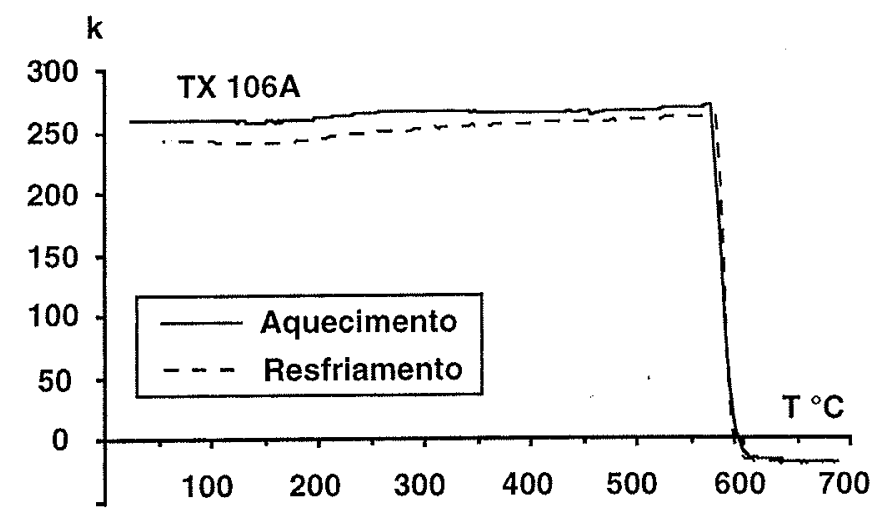

Figura 7 - Curva termomagnética representativa do Batólito de Teixeira. Note a queda abrupta de suscetibilidade en torno de $570^{\circ} \mathrm{C}$.

Propriedades de histerese As curvas de histerese foram obtidas com um Magnetômetro de Amostra Vibrante (VSM) do Laboratório de Paleomagnetismo da Universidade de São Paulo. Este equipamento aplica um campo magnético que oscila de $1000 \mathrm{mT} \mathrm{a}-1000 \mathrm{mT}$ em fragmentos de rocha de 0.2 a $0.3 \mathrm{~cm}^{3}$. Os dados de histerese são utilizados principalmente na elucidação da estrutura de domínios e granulometria da fração ferrimagnética. Foram estudadas 18 amostras todas provenientes das zonas de falha magneticamente anômalas do BT (Fig. 3).

As curvas de histerese são feitas em campo magnético suficientemente forte para saturar a fração ferrimagnética. A porção linear posi tiva da curva em campo superior a $200 \mathrm{mT}$, fornece o componente de suscetibilidade da matriz (paramagnética + antiferromagnética) (Fig. 8). Na curva de histerese, a suscetibilidade total $(\mathrm{k})$ da amostra é a somatória das contribuições ferrimagnética $\left(\mathrm{k}_{\mathrm{f}}\right)$ e da matriz $\left(\mathrm{k}_{\mathrm{mal}}\right)$. No exemplo da Figura 8, uma contribuição de $91 \%$ é fornecida pela tração ferrimagnética para uma amostra cuja suscetibilidade total é de $1.06 \mathrm{x}$ $10^{-3}$ SI A parte linear da curva em campo forte é em seguida rotacionada para a horizontal para isolar o componente ferrimagnético e fornecer os valores de magnetização de saturação $\left(M_{s}\right)$, magnetização de remanescência $\left(M_{10}\right)$, campo coercitivo $\left(\mathrm{H}_{\mathrm{c}}\right)$ e coercitividade de remanescência $\left(\mathrm{H}_{*}\right)$. As curvas de histerese mostram que a suscetibilidade é dominada pela magnetita, como sugerido pela estreita cintura do loop próximo à origem do gráfico, o que é típico de minerais magnéticos de baixa coercitividade. A razão $\mathrm{M}_{r} / \mathrm{M}_{\text {varia de }} 0,019$ a 0,108 (Tabela 4), com uma média de 0,044. Esses valores situam-se próximos aos valores propostos para grãos multidomínio de magnetita (Dunlop 1986; Heider et al. 1996). Os valores de H situam-se entre 1,167 a $13,981 \mathrm{mT}$, com um valor médio de $4,89 \mathrm{~m}$ t. As razões $\mathrm{M}_{\mathrm{r}}$ ' $\mathrm{M}$ e $\mathrm{H} / \mathrm{H}$ quando plotadas no diagrama de Day et al. (1977) (Fig. 9), confirmam a natureza multidomínio a pseudo-monodomínio dos grãos de magnetita. Em três amostras a coercividade remanescente elevada $\left(\mathrm{H}_{\mathrm{cr}}>100 \mathrm{mT}\right)$ indica a presença de hematita $(77 \mathrm{~B})$ e/ou mis 
turas de hematita com um mineral de coercividade baixa (76A e $106 \mathrm{~A})$, provavelmente magnetita.

Uma estimativa da granulometria da fração que fornece o sinal magnético pode ser obtida através da relação entre o tamanho dos grãos de magnetita, do campo coercitivo $\left(\mathrm{H}_{\mathrm{c}}\right)$ e da razão $\mathrm{M}_{\mathrm{rs}} / \mathrm{M}_{\mathrm{s}}$ (Hunt et al. 1995). Foi estudada a variação destes parâmetros em correspondência com a granulometria de grãos sintéticos produzidos por: i) precipitação aquosa a baixas temperaturas ou por recristalização hidrotermal a altas temperaturas; ii) prensamento e peneiramento de grandes cristais e, iii) cerâmicas vítreas ricas em ferro produzidas em altas temperaturas. Comparados os parâmetros de histerese do BT com grãos formados por recristalizacão hidrotermal em alta temperatura, obte-se grãos magnéticos cuja granulometria varia de 0,1 a $10 \mu \mathrm{m}$.

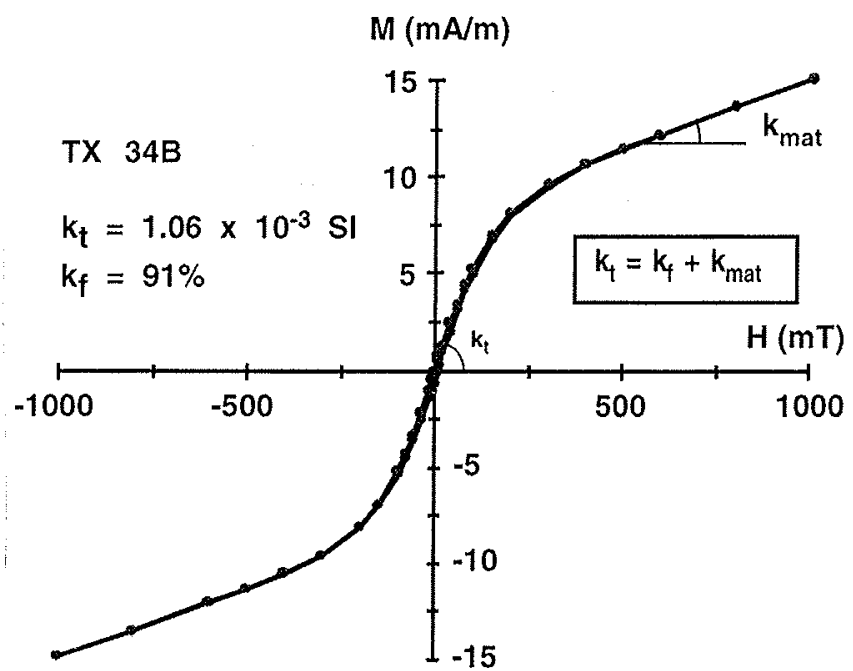

Figura 8 - Ciclo de histerese para amostra \#34B com suscetibilidade total $\left(k_{t}\right)$ de $1.06 \times 10^{-3}$ SI. A inclinação da curva em campo indutor $(H)$ superior a 500 $m T$ é proporcional a contribuiçáo dos minerais magnéticos da matriz ( $k_{\text {mat }}$ fraçäo para-e antiferromagnética). A contribuiçäo ferrimagnética $\left(k_{f}\right)$ é calculada subtraindo a suscetibilidade da matriz da susceptibilidade total

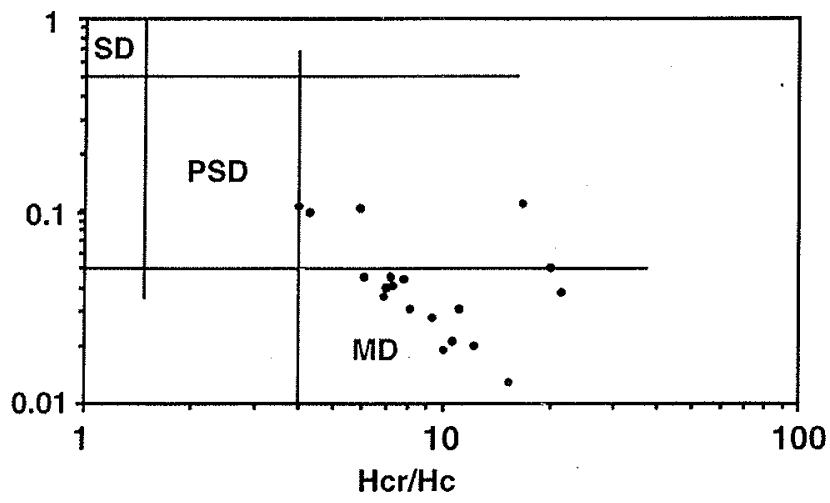

Figura 9 - Diagrama de Day et al. (1977) com os campos da magnetita com estrutura em dominio simples (SD), pseudo-domínio simples (PSD) e multidomínio. As amostras do Batólito de Teixeira caem principalmente no campo das magnetitas multidomínio (MD).
Tabela 4-Parametros de histerese do granito de Teixeira. Hc: campo coercitivo; Hcr: campo coercitivo remanente; $M s$ : magnetização a saturação, Mrs: magnetização a saturação remanente; $k_{i}$ : suscetibilidade total. Os parametros de histerese da hematita, da magnetita multidominio (MD) e dominio simples (SD) foram compilados em Day et al. (1977), Dunlop (1986) e Heider et al. (1996). A presença de hematita em algumas amostras (sublinhado) é indicada pelo elevada coercividade remanente.

\begin{tabular}{|c|c|c|c|c|c|}
\hline & $\mathrm{Hc}(\mathrm{mT})$ & $\mathrm{Hcr}(\mathrm{mT})$ & Mrs/Ms & $\mathrm{Hcr} / \mathrm{Hc}$ & \\
\hline Hematita & $>135$ & $>200$ & $0.45-0.60$ & $1.38-1.90$ & \\
\hline Magnetita SD & $10.0-40.0$ & $20.0-50.0$ & $0.50-0.90$ & $<2$ & \\
\hline Magnetita MD & $2.5-4.0$ & $<30$ & $0.01-0.03$ & $>4$ & \\
\hline \multicolumn{6}{|r|}{$k_{1}\left(10^{-3} \mathrm{SI}\right)$} \\
\hline $01 \mathrm{~A}$ & 4.33 & 32.47 & 0.040 & 6.98 & 1.079 \\
\hline $02 \mathrm{~B}$ & 2.43 & 30.00 & 0.046 & 7.21 & 0.214 \\
\hline $03 \mathrm{~A}$ & 2.51 & 28.82 & 0.105 & 5.92 & 0.280 \\
\hline $29 \mathrm{~A}$ & 11.61 & 50.38 & 0.098 & 4.27 & 4.821 \\
\hline $30 \mathrm{~A}$ & 3.98 & 28.24 & 0.036 & 6.88 & 3.405 \\
\hline $33 \mathrm{~B}$ & 4.77 & 31.77 & 0.046 & 6.03 & 1.060 \\
\hline $34 \mathrm{~B}$ & 6.23 & 39.37 & 0.107 & 3.97 & 0.321 \\
\hline $35 \mathrm{~B}$ & 3.54 & 42.14 & 0.031 & 11.16 & 1.607 \\
\hline $37 \mathrm{~B}$ & 3.49 & 30.16 & 0.031 & 8.13 & 1.709 \\
\hline $53 \mathrm{~A}$ & 2.41 & 26.76 & 0.021 & 10.71 & 2.256 \\
\hline $76 \mathrm{~A}$ & 6.02 & 133.33 & 0.051 & 20.10 & 2.296 \\
\hline $77 \mathrm{~B}$ & 13.92 & 241.37 & 0.011 & 16.82 & 2.635 \\
\hline $92 \mathrm{~A}$ & 1.62 & 25.00 & 0.013 & 15.27 & 0.539 \\
\hline $94 \mathrm{~B}$ & 3.75 & 38.33 & 0.028 & 9.421 & 0.753 \\
\hline $96 \mathrm{~A}$ & 1.98 & 20.00 & 0.019 & 10.07 & 10.311 \\
\hline $106 \mathrm{~A}$ & 4.53 & 101.28 & 0.038 & 21.66 & 8.158 \\
\hline $107 \mathrm{~B}$ & 4.60 & 33.95 & 0.041 & 7.31 & 24.073 \\
\hline $118 \mathrm{~B}$ & 4.24 & 33.64 & 0.044 & 7.82 & 3.674 \\
\hline $120 \mathrm{~A}$ & 2.27 & 28.17 & 0.020 & 12.31 & 11.038 \\
\hline
\end{tabular}

Caracterização mineralógica A identificação mineralógica foi realizada no Laboratório de Microscopia Eletrônica do Departamento de Geologia Sedimentar e Ambiental do IG/USP. Os difratogramas composicionais foram obtidos através da microanálise por energia dispersiva acoplada ao microscópio eletrônico.

Ao microscópio eletrônico a magnetita é o óxido dominante. Os grãos são, em geral, idiomórficos a subidiomórficos variando de 10 a $180 \mu \mathrm{m}$, com alguns cristais exibindo partição paralela às faces octaédricas (Fig. 10A). O difratograma composicional em vários pontos do centro e da borda da magnetita não detectou a presença do elemento $\mathrm{Ti}$, como já havia sido sugerido pela análise das curvas termomagnéticas. Em algumas seções foi observado a presença de lamelas de hematita ocupando os planos octaedrais da magnetita (Fig. 10B). Nestas amostras foram também observadas cavidades preenchidas com alanita formando colunas ou botões (Fig. 11). No difratograma destes grãos foram encontrados altos teores de Terras Raras, com picos nos elementos Ce, La, e Nd (Fig. 12A). Além da magnetita e alanita, foram identificados filonetes discordantes de barita $\left(\mathrm{BaSO}_{4}\right)$ cortando os minerais silicatados e a magnetita (Fig. 13 e 12B).

DISCUSSÃO A formação da magnetita no BT está provavelmente relacionada a processos hidrotermais tardios gerados em regime crustal relativamente raso, como sugerido pela relação entre as anomalias de suscetibilidade e a presença de falhas e fraturas no interior do dique. Processos metassomáticos promovendo a fuga de álcalis e enriquecimento de $\mathrm{Fe}_{2} \mathrm{O}_{3}+\mathrm{FeO}, \mathrm{CaO}$, $\mathrm{TiO}_{2}$ e $\mathrm{P}_{2} \mathrm{O}_{5}$ foram igualmente detectados nos estudos geoquímicos de Medeiros (1995). A reação sugerida para a formação da magnetita é a desestabilização da biotita rica em ferro (anita) sob condições de alta fugacidade de oxigênio, gerando Kfeldspato e magnetita (Wones e Eugster 1965):

$\mathrm{KFe}_{3} \mathrm{AlSi}_{3} \mathrm{O}_{10}(\mathrm{OH})_{2}+\mathrm{O}_{2} \rightarrow \mathrm{KAlSi}_{3} \mathrm{O}_{8}+\mathrm{Fe}_{3} \mathrm{O}_{4}+\mathrm{H}_{2} \mathrm{O}$

Tabela 3 - Resultados do tratamento estatístico para as variabilidades de K (suscetibilidade) e P (anisotropia) separados em dois subgrupos: variabilidades de K e P maiores $(A)$ e menores $(B)$ que $0,5 \times 10^{-3}$ SI. São mostrados os valores absolutos de cada variabilidade e entre parênteses a porcentagem dentro da variabilidade total.

\begin{tabular}{|c|c|c|c|c|c|c|c|c|}
\hline & \multicolumn{2}{|c|}{ ENTRE AMOSTRAS S $_{A}$} & \multicolumn{2}{|c|}{ ENTRE CILINDROS S ${ }_{\text {c }}^{2}$} & \multicolumn{2}{|c|}{ ENTRE ESTAÇÕES $S_{\text {: }}^{2}$} & \multicolumn{2}{|l|}{ TOTAL S $_{r}^{2}$} \\
\hline & $\mathrm{A}$ & $\mathrm{B}$ & $\mathrm{A}$ & $\mathrm{B}$ & $\mathrm{A}$ & $\mathrm{B}$ & $\mathrm{A}$ & $\mathrm{B}$ \\
\hline$K$ & $\begin{array}{l}473215.8 \\
(2.27 \%)\end{array}$ & $\begin{array}{l}2402.84 \\
(24.52 \%)\end{array}$ & $\begin{array}{l}6854187.1 \\
(32.84 \%)\end{array}$ & $\begin{array}{l}4477.55 \\
(45.68 \%)\end{array}$ & $\begin{array}{l}13541658.5 \\
(64.89 \%)\end{array}$ & $\begin{array}{l}2920.21 \\
(29.80 \%)\end{array}$ & $\begin{array}{l}20869061.4 \\
(100 \%)\end{array}$ & $\begin{array}{l}9800.6 \\
(100 \%)\end{array}$ \\
\hline$P$ & $\begin{array}{l}0.001326 \\
(11.71 \%) \\
\end{array}$ & $\begin{array}{l}0.000215 \\
(35.89 \%) \\
\end{array}$ & $\begin{array}{l}0.002664 \\
(23.53 \%)\end{array}$ & $\begin{array}{l}0.00011 \\
(18.4 \%) \\
\end{array}$ & $\begin{array}{l}0.00733025 \\
(64.76 \%) \\
\end{array}$ & $\begin{array}{l}0.000274 \\
(45.74 \%) \\
\end{array}$ & $\begin{array}{l}0.01132025 \\
(100 \%)\end{array}$ & $\begin{array}{l}0.000599 \\
(100 \%) \\
\end{array}$ \\
\hline
\end{tabular}



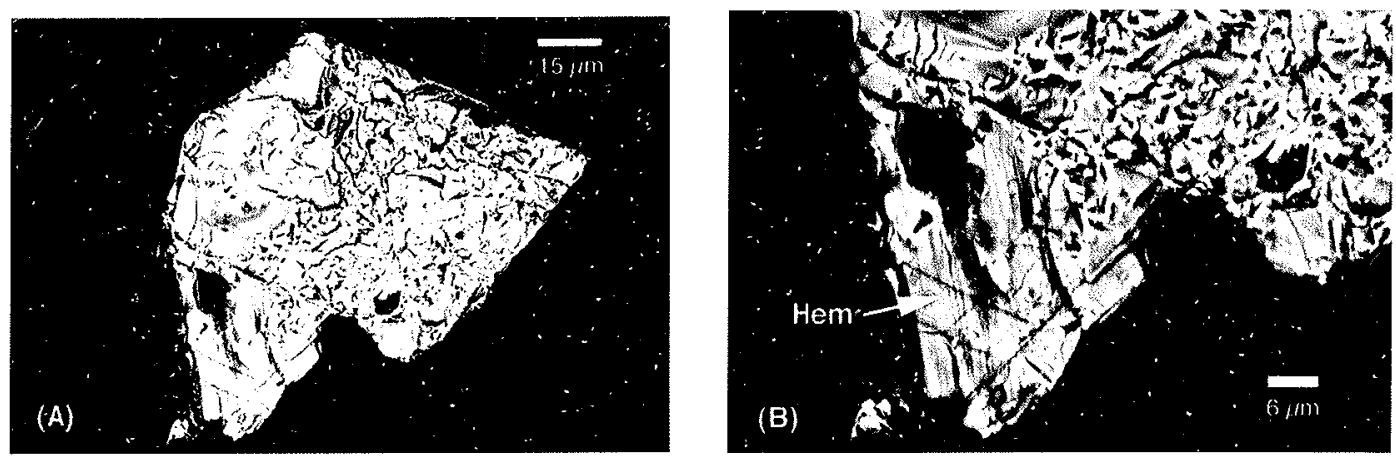

Figura 10 - Cristal de magnetita (A) mostrando finas lamelas descontinuas de hematita (B).

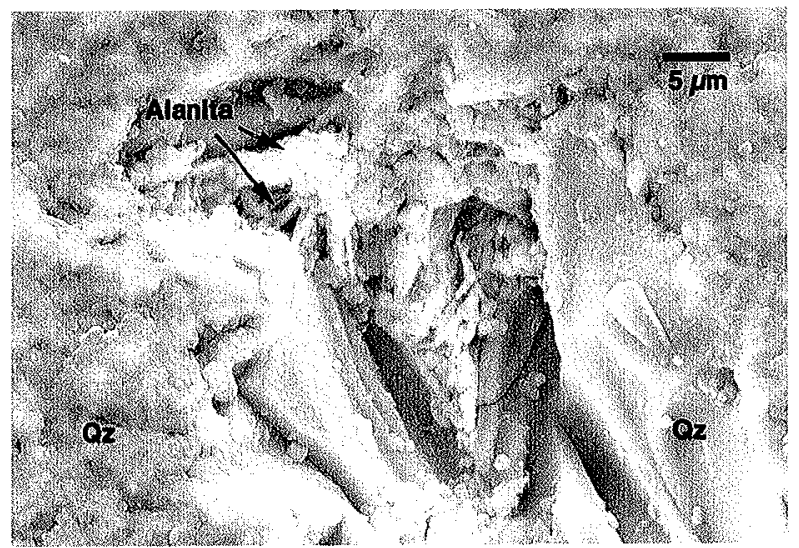

Figura 11 - Cristais fibrosos de alanita preenchendo cavidade em grão de guartzo. Zona de Cisalhamento de Itapetim (estaçăo \#92).
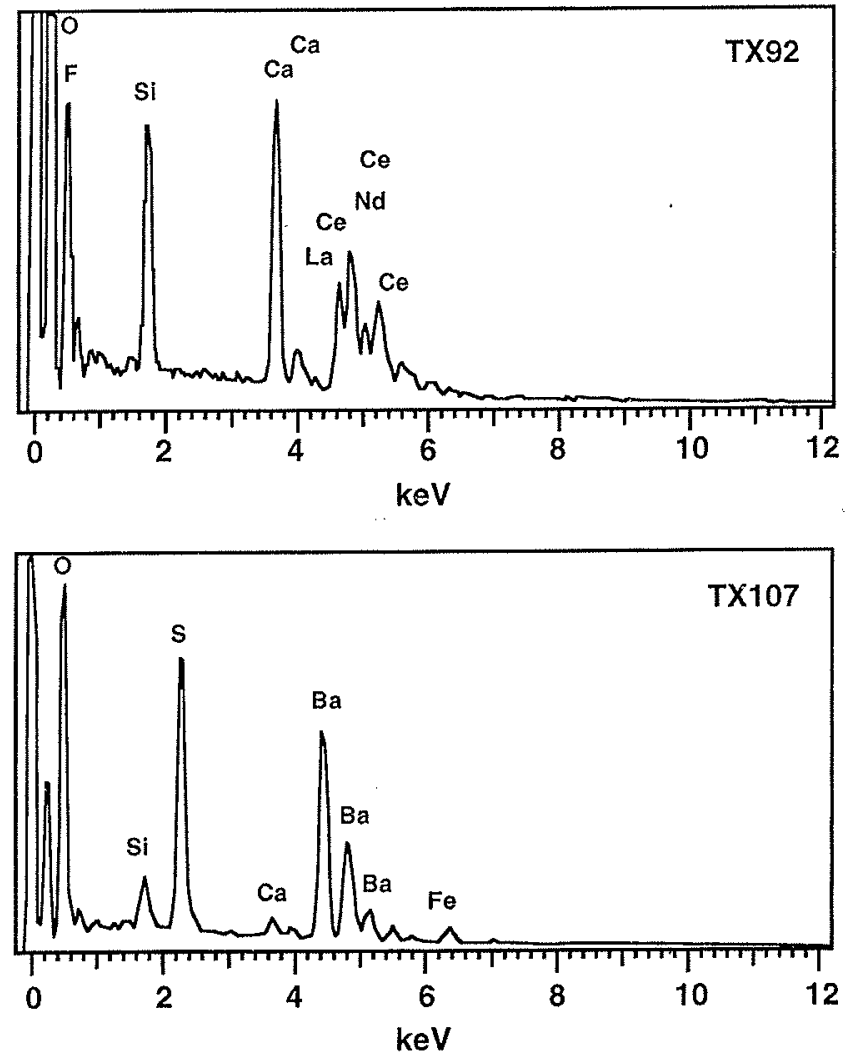

Figura 12 - Difratograna composicional de alanita (TX92) e barita (TX107) em amostras da Zona de Cisalhamento de Itapetim cortando o Batólito de Teixeira.

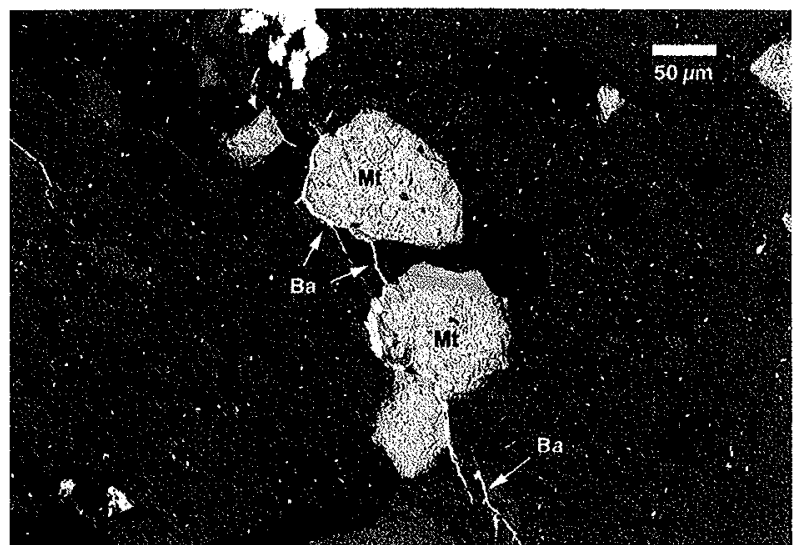

Figura 13 . Veios de barita cortando magnetita e feldspato. Zona de Cisalhamento de Itapetim (estação \#107).

Anita

K-feldspato magnetita

Lamelas de hematita ocupando planos octaedrais da magnetita sugerem processos de martitização desencadeados pelo aumento da fugacidade de oxigênio, de acordo com a reação:

$$
\underset{\text { magnetita }}{2 \mathrm{Fe}_{3} \mathrm{O}_{4}+\mathrm{O}_{2}} \rightarrow \underset{\text { hematita }}{3 \mathrm{Fe}_{2} \mathrm{O}_{3}}
$$

A formação de barita $\left(\mathrm{BaSO}_{4}\right)$ ocupando fissuras provavelmente ocorre na desestabilização do feldspato potássico e mica que liberam $\mathrm{Ba}^{+2} \mathrm{O}$ bário, solubilizado na fase fluida, seria posteriormente precipitado em microfraturas que cortam os silicados. A assembléia magnetita + hematita + barita indica que a alteração hidrotermal associada aos cisalhamentos ocorreu sob alta fugacidade de oxigênio (Crerar e Barnes 1976; Foster 1993). A presença de cavidades preenchidas com alanita é o testemunho de corrosão relacionado à passagem de um fluido circulando entre microfissuras nos silicatos.

A variação da suscetibilidade magnética no BT sugere que a evolução do granitóide passou por dois episódios principais. O primeiro consiste na colocação de um magma granítico "a ilmenita", isto é, com o $\mathrm{Fe}^{+2}$ retido na cristalização dos silicatos ferromagnesianos, tais como a biotita e o anfibólio. A susceptibilidade, neste caso, é controlada principalmente pela presença dos minerais máficos. No segundo estágio, com o magma já completamente cristalizado, o dique granítico é deformado pela ação de zonas de cisalhamento de natureza frágil a frágil-dúctil, com concomitante circulação de fluidos hidrotermais apresentando elevada fugacidade de $\mathrm{O}_{2}$. $\mathrm{O}$ intercrescimento de hematita na magnetita e a formação tardia de barita é sugestivo de um aumento progressivo da fugacidade de $\mathrm{O}_{2}$ nos estágios finais do processo hidrotermal.

A origem das anomalias magnéticas lineares poderia assim ser explicada pela cristalização de óxidos (magnetita) percolando zonas de cisalhamento e fraturas. Afastando-se destas zonas, a suscetibilidade 
decresce com a diminuição do teor de magnetita na rocha. Situação semelhante foi encontrada no sienito de Triunfo (Archanjo e Bouchez, 1997), onde a magnetita tardia cristaliza-se no contato dos grãos de aegirina-augita ou ao longo de seus planos de clivagem. Estes resultados conseguem explicar, satisfatoriamente, a origem das anomalias magnéticas detectadas nos estudos de Scheid \& Ferreira (1991; 1993), descartando um dos modelos propostos que atribuíam a corpos básicos a origem das anomalias

A ZCI e as ocorrências de ouro O ouro do Distrito de Itapetim é formado nos estágios finais de um evento de deformação dúctil, em condições retrometamórficas de fácies xisto verde, associado a alteração hidrotermal (Coutinho 1994; Silveira 1997; Silva 1999). Além do ouro incrustado em veio de quartzo, são observados sulfetos de $\mathrm{Cu}$ (pirita, calcopirita), $\mathrm{Pb}$ (galena) além de material carbonoso (Coutinho 1994), indicando que a circulação dos fluidos mineralizantes ocorreu em ambiente dominantemente redutor. Por outro lado, a ZCI ao penetrar o BT exibe feições de deformação crustal rasa e mineralogia típica de ambiente oxidante.

A clara distinção desses setores da Zona de Cisalhamento de Itapetim (ZCI) enseja várias interpretações. Uma delas seria considerar que o aporte de fluido que permitiu o transporte do ouro, juntamente com complexos reduzidos de enxofre, foi progressivamente modificado após a precipitação do minério e dos sulfetos metálicos. A elevação da fugacidade de oxigênio juntamente com a evolução da deformação para níveis mais superiores da crosta, como observado no BT, tornou o fluido mais oxidante fornecendo condições para a cristalização de óxidos, como magnetita e hematita (Silva e Legrand, 1997).

Outra possível interpretação diz respeito à diferentes fontes e caminhos que o fluido possa ter tomado durante a sua percolação, os quais poderiam alterar sobremaneira as suas condições geoquímicas iniciais. Dessa forma, o fluido responsável pelas mineralizações pode ter tido como fonte um magma cristalizando sob baixa fugacidade de oxigênio, gerando um fluido de natureza redutora e sulfetada. Posteriormente o fluido percolante nas falhas que cortam o $\mathrm{BT}$ podem ter interagido com rochas ou percorrido caminhos que o tornaram mais oxidante. A distinção entre os diferentes modelos poderia ser investigadas atravé do estudo de traçadores isotópicos e inclusões fluidas dos veios de quartzo situados ao longo da $\mathrm{ZCI}$.

CONCLUSÕEs O Batólito Granítico de Teixeira apresenta suscetibilidade magnética relativamente baixa, inferior a $0.5 \times 10^{-3} \mathrm{SI}$ em $60 \%$ de sua superfície, indicando uma significativa contribuição dos minerais paramagnéticos (biotita e anfibólio) sobre a suscetibilidade total da rocha. Os valores de suscetibilidade mais elevados estão restritos às regiões de borda e às zonas cisalhadas que cortam o corpo. Nestes domínios, a suscetibilidade pode localmente atingir magnitudes da ordem de $10^{-2} \mathrm{SI}$. Medidas de temperatura de Curie e a observação ao microscópio eletrônico de varredura indicaram que a suscetibilidade elevada é fornecida pela magnetita pobre em Ti As curvas de histerese mostraram que a estrutura da magnetita é do tipo multidomínio, sendo os parâmetros de histerese (coercividade e magnetização remanescente) controlados pelos grãos mais finos $(<10$ $\mu \mathrm{m}$ ). A forte coercividade remanenscente em algumas amostras sugere a presença de hematita. A presença de hematita e barita associada a magnetita, indica que os processos hidrotermais que conduziram às anomalias de suscetibilidade foram relacionados a uma fonte hidrotermal de elevada fugacidade de oxigênio, com a circulação de fluidos controlada pela deformação cisalhante regional.

Agradecimentos Este trabalho foi financiado pelo projeto " $\mathrm{Ge}$ ologia e Mineralizacões de Au-W nas Faixas Seridó e Cachoeirinha Nordeste do Brasil" (PADCT/FINEP ). Agradecemos ao Dr. José Salim, coordenador do projeto, pelo incentivo e apoio para o desenvolvimento deste trabalho, e ao $\mathrm{CNPq}$ pela concessão de bolsas de Mestrado (RGL) e Produtividade em Pesquisa (CJA). O manuscrito foi significativamente melhorado com a contribuição de dois revisores anônimos.

\section{Referências}

Archanjo C.J \& Bouchez J.L. 1997. Magnetic fabrics and microstructures of the postcollisional aegirine-augite syenite pluton of Triunfo, north-east Brazil. Journal of Structural Geology, 19: 849-860

Archanjo C.J., Macedo J.W.P., Galindo A.C., Araújo M.G.S. 1998. Brasiliano crustal extension and emplacement fabrics of the mangerite-charnockite pluton of Umarizal North-east Brazil. Precambrian Research, 87: 19-32.

Archanjo, C.J., Silva E. R. Caby R. 1999. Magnetic fabric and pluton emplacement in a transpressive shear zone system: The Itaporanga porphyritic granitic pluton

Benn K., Ham N.M., Pignotta G.S. 1998. Emplacement and deformation of granites during transpression: magnetic fabrics of the Archean Sparrow pluton, Slave Province, transpression: magnetic fabrics of the Archean Sparrow

Borradeile G. \& Henry B. 1997 . Tectonic applications of magnetic susceptibility and its anisotropy. Earth Science Reviews, 42: 49-93.

Bouchez J.L. 1997. Granite is never isotropic: an introduction to AMS studies of granitic rocks. In: J.L. Bouchez, D. Hutton \& W.E. Stephens (eds.), Granite: From Segregation of Melt to Emplacement Fabrics, Dordrecht: Kluwer Academic, 95-112

Coutinho M.G.N. 1994. The geology of shear-zone hosted gold deposits in Northeast Brazil. PhD Thesis, University of London, London, 340p.

Crerar D.A. \& Barnes H.L. 1976. Ore solution chemistry v. solubilities of chalcopyrite and chalcocite assemblages in hydrotermal solution at $200^{\circ}$ to $350^{\circ} \mathrm{C}$. Economic Geology: 71, 772-794

Day R., Fuller M.D., Schmidt V.A. 1977. Hysteresis properties of titanomagnetites: grainsize and composional dependence. Physics of the Eath and Planetary Interiors. 13 260-267.

Dunlop D.J. 1986. Hysteresis properties of magnetite and their dependence on particle size a test of pseudo-single domain remanence models. Jounal of Geophysical Research, 91: $9569-9584$

Foster R.P. 1993. Chemical evolution of fluids and precipitation of gold in mesothermal lode gold deposits. In: J. Painel et al. (ed.), Geofluids's 93, Torquay, England, 378-382.

Heider F., Zitzelsberger A., Fabien K. 1996. Magnetic susceptibility and remanent coercive force in grown magnetite crystals from 0.1 to $6 \mathrm{~mm}$. Physics of the Earth and Planetary Interiors, 93, 239-256.

Hunt C.P., Moskowitz B.M., Banerjee S.K. 1995. Magnetic Properties of rocks and minerals. In: Rock Physics and Phase relations, A Handbook of physical constants AGU Reference Sheif $3,189-204$.
Ishihara S. 1977. The magnetite series and ilmenite series granitic rocks. Mining Geology 27: $293-305$

Medeiros V.C. 1995. Sensoriamento remoto e petrologia de granitóides brasilianos no Dominio da Zona Transversal, Nordeste do Brasil. UFPE. Dissertação de Mestrado, $149 \mathrm{p}$.

Neter J., Wasserman W., Kutner M.H. 1990. Applied Linear Statistical Models. 3ed. Boston, Irwin. $1181 \mathrm{p}$

Rochette P., Jackson M., Aubourg C. 1992. Rock Magnestim and interpretation of anisotropy of magnetic susceptibility. Reviews in Geophysics: 30: 229-237.

Santos E.J. \& Medeiros V.C. 1997. Constraints from granitic plutonism on Proterozoic crustal growth of the Zona Transversal domain, Borborema Province, NE, Brazil II ISGAM, Salvador, Anais, 237-239.

Scheid C. \& Ferreira C.A. 1991. Programa Levantamentos Geológicos Básicos do Brasil: Carta geológica, carta metalogenético-previsional-Escala l: 100.000 (folha SB 24Carta geológica, carta metalogenético-previsional - Escala I: 00.000 (jolha SB 24-

Scheid C. \& Ferreira C.A. 1993. Programa Levantamentos Geológicos Básicos do Brasil. C. \& Ferreira C.A. 1993. Programa Levantamentos Geologicos Basicos do Brasit:
Carta gentógica, carta metalogenético-previsional - Escala 1:100.000 (folha $S B$ 24Carta geológica, carta metalogenético-previsional-Escala 1:100.000 (folta
Z-D-ll-Jiazeirinho). Estado da Paraiba. Brasília, DNPM/CPRM. 148p.

Silva S.G. \& Legrand J.M. 1997 . A relação entre mineralizações de ouro e barita numa área a Oeste de Caicó (RN). XVII Simpósio de Geologia do Nordeste, Fortaleza, 478 483

Silva S.G. 1999. Geoquimica dos Fluidos e Estudos de balango de massa en mineralizaçóes de oumo em veios de anartzo dos Distritos auriferos de Mäe D'água e Itapetim (PB). PPGeo-UFRN, Dissertação de Mestrado, 126p.

Silveira FV 1997 Mapeanento Geológico, controle estrutural e atividade hidrotermal do Distrito Aurifero de ltapetim (PE/PB): Setores Sertãozinho. Piedade. Pinenteiras e Gurguéia. UFRN, Natal, Relatório de Graduação, 59p.

Wones D.R. \& Eugster. H.P. 1965. Stability of biotite: theory and application. American Mineralogist. 50:1228-1272
Manuscrito A-1120 Recebido em 15 de setembro de 1999 Revisão dos autores em 10 de marco de 2000 Revisão aceita em 20 de março de 2000 